
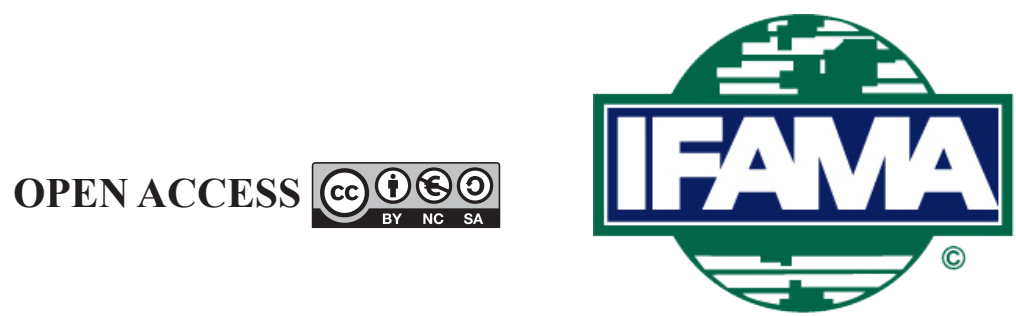

International Food and Agribusiness Management Review

Volume 23, Issue 4, 2020; DOI: 10.22434/IFAMR2019.0199

Received: 25 November 2019 / Accepted: 6 June 2020

\title{
Tomato seed value chain analysis and seed conditioning among seed companies in Uganda
}

\section{RESEARCH ARTICLE}

\author{
Sharon M. Tusiime ${ }^{\mathrm{a}}$, Gail R. Nonnecke ${ }^{\circledR b}$ and Helen H. Jensen ${ }^{\mathrm{c}}$ \\ ${ }^{a}$ Graduate student, ${ }^{b}$ Morrill Professor and University Professor, Department of Horticulture, \\ Iowa State University, 106 Horticulture, 2206 Osborn Drive, Ames, IA 50011-4009, USA \\ ${ }^{c}$ Professor Emerita, Department of Economics, Iowa State University, $578 E$ \\ Heady Hall, 518 Farm House Lane, Ames, IA 50011-1054, USA
}

\begin{abstract}
Tomatoes increase nutritional food security and income among Ugandan smallholder farmers who have limited access to high quality seed. The objective of this study was to analyze the current tomato seed value chain for Uganda. Survey responses determined roles of key participants, including Ministry of Agriculture, Animal Industry and Fisheries (MAAIF) for regulation and certification; National Agricultural Research Organization for breeding cultivars and seed multiplication; Makerere University for education and research; commercial seed companies for seed importation and conditioning; seed distributors for sales; and smallholder farmers as savers and end users of seed. Challenges included an inefficient domestic seed distribution system, technical constraints in seed production and conditioning by seed companies, inadequate networks and communication among the seed industry's key participants, and partial regulation of the seed industry. Seed companies played a key role in seed conditioning processes. Companies imported all tomato seeds into Uganda and stated germination as their primary goal for quality. Challenges for seed companies included assistance from MAAIF to regulate and certify seed and access to improved technologies. Attaining high quality seed by commercial Uganda-parent companies will require additional investment and training of seed technologists for domestic testing and seed quality assurance.
\end{abstract}

Keywords: tomato seed value chain, value chain analysis, seed conditioning, Uganda JEL code: Q13, Q12, O17

(1)Corresponding author: nonnecke@iastate.edu 


\section{Introduction}

Uganda is located in East Africa and agriculture is the foundation of its economy. About $65 \%$ of its population depend on the agriculture sector and derive their livelihoods from subsistence farming, and agriculture contributes about $46 \%$ of the total export earnings (MAAIF, 2018). Before 1968, Uganda's seed industry was primarily informal and cultivated varieties (cultivars) of crops were exchanged through a farmer-to-farmer system. By 1995, the government had monopolized the seed industry through a program called the Uganda Seed Project, which handled the production, processing, and marketing of seed. However, all of these seed processes became excessive for the Uganda Seed Project to handle over time and it was transformed into a public liability company, Uganda Seed Ltd., which was later distributed to a private seed company. The exit of the government from seed production and distribution encouraged private entrepreneurs to establish additional seed companies. There are at least 26 locally registered companies involved in production, processing, and marketing of seed across all crops (Larson and Mbowa, 2004; Mastenbroek and Ntare, 2016).

A seed system involves both economic and social mechanisms to meet farmers' demand for seeds and their various traits (Kansiime and Mastenbroek, 2016). Seed systems include interrelated institutions that develop new cultivars, and produce, test, certify, and market seed, and both formal and informal seed systems that support and supply the agriculture sector with seed inputs. In the formal seed sector, seed quality is assured through seed conditioning processes (cleaning, sorting, grading, application of any seed treatments such as fungicides, packaging, and storage) and quality testing (germination and vigor). Within the informal seed sector, little-to-no improved value is added to the seed itself, due to limited seed quality assurance and lack of seed conditioning processes. In Uganda, the informal sector supplies the majority of seeds compared to the formal sector (Lwakuba, 2012). Much focus on seed systems is placed on seeds of staple crops that are mainly cereals. Vegetable crops including tomatoes have received very limited focus to date, despite the fact that vegetables are important for nutritional food security and provide high-value crops for markets. Tomatoes are the most widely grown and consumed vegetable in Uganda and grown by using seeds.

Tomatoes are high-value crops that improve income and food security among smallholder farmers in Uganda (Ssebuliba, 2010). Seed of high quality is essential for farmers to successfully produce tomatoes, and farmers' food security and livelihoods depend on the availability of quality seed in the farming community (CEAPRED, 2014; Gauchan et al., 2014; Ssebuliba, 2010). A secure seed system ensures that high-quality seed is produced, available and affordable to the end users (Sperling and Cooper, 2003). Uganda's formal seed system of commercialized seed companies and distributors produces $20 \%$ of the seed, while the informal seed system of farmers who save seed or purchase seed from other smallholder farmers contributes $80 \%$ (Lwakuba, 2012). Both seed systems are essential, but improved efficiency in both of these seed systems would benefit end-users and result in increased tomato production. Currently, it is difficult for smallholder farmers to access improved and good quality tomato seeds due to various challenges, including, but not limited to, inefficient seed distribution systems, presence of poor quality seed that does not germinate and/ or is not the stated cultivar (locally called 'counterfeit' seed), and improper storage. A large share of seed on the market (30-40\%) is a combination that is not the stated cultivar or is a mixture of different cultivars and/ or crop species. Some of these challenges have been identified in the current national seed policy document (MAAIF, 2018) and by others (Ssebuliba, 2010). High quality tomato seeds protect germination capability by being 'conditioned', and provide genetic reproducibility by being the stated cultivar.

Value chains allow a product to move from one chain actor to another while gaining and protecting added value. In the case of fresh tomato fruit, integrated value chains have been used in the past to determine and develop attributes being added and target interventions to improve production and handling of the fresh fruit (Hellin and Meijer, 2006; Ssejjemba, 2008). However, no studies to date have focused on the tomato seed system and its contribution to value in tomato production in Uganda. This study aims to analyze the tomato seed system by determining its key participants, their roles and challenges, and mapping the current tomato seed value chain for Uganda. Understanding the key actors and their roles in the Ugandan vegetable seed system can target policies and interventions to improve the development and provide support for the 
supply of quality tomato seed. Commercial seed companies are one of the key participants of the tomato seed industry and their role is featured to better understand the current tomato seed production and conditioning processes and procedures and opportunities for establishing seed quality in Uganda. Improving Ugandan seed production and conditioning also will support smallholder farmers' access to better quality seeds.

\section{Methods}

The tomato seed value chain was analyzed and mapped using value chain analysis (Hellin and Meijer, 2006). The value chain map indicates the flow of raw materials/inputs (seed) from production to consumption (enduser) and reflects the value-added functions or attributes at each point in the chain. This mapping of market participants, institutions, and linkages allows better understanding of the market relationships and functions. In the case of the Uganda seed system, both formal and informal sectors are important. By identifying the participants and linkages, the value chain analysis can be used to identify and target interventions aimed at improving the quality and distribution of seeds in the system. Surveys that were implemented in 2015 and 2016 obtained data from key participants in the tomato seed system in Uganda. The surveys in 2015 focused on developing the value chain mapping, and the surveys in 2016 provided additional information on the procedures and value added by seed companies. A detailed description of the survey methods is presented below and in the supplementary materials.

\subsection{Study area}

In June-August 2015, a survey was conducted with the key participants who play a major role in the tomato seed industry in Uganda. Key participants included commercial seed companies, federal Ministry of Agriculture, Animal Industry and Fisheries (MAAIF), Uganda's National Agriculture Research Organization (NARO), Makerere University (MAK), seed distributors, and smallholder farmers. In Uganda, seed companies and MAK were located in Kampala, NARO and MAAIF in the Wakiso District, and smallholder farmers in the survey lived in the Kamuli District (Supplementary Figure S1).

\subsection{Sample size and participants}

All participants were selected because of their involvement in the tomato seed sector. The sample included one official from each of MAAIF, NARO, and MAK, representatives from six tomato seed companies, and a sample of smallholder farmers. Surveys were conducted orally with the commissioner for crop inspection and certification (MAAIF), senior research officer for Horticulture and Oil Palm program (NARO), a faculty member of horticultural sciences (MAK), vegetable seed managers in each of the six seed companies, and a stratified random sample of 346 smallholder farmers in the Kamuli District who grew tomatoes. The target sample size of smallholder farmers in the study was determined to be 384 and was proportionate to the parish household population (Fisher et al., 1983; Mugenda and Mugenda, 1999). To ensure representation of the entire population, a stratified random sampling technique was used in three sub-counties and 10 parishes of the Kamuli District. The survey included representative geographic strata and a high participation rate (Supplementary material: sample size and techniques). We were able to survey 346 smallholder farmers, or $90.1 \%$ of the target sample size.

\subsection{Survey instrument for tomato seed systems in Uganda}

Research approval was obtained from Iowa State University's Institutional Review Board (IRB ID: 15-374) and the Uganda National Council of Science and Technology (UNCST: A 501). The survey tool was comprised of open-ended and multiple-choice questions and was reviewed by Iowa State University faculty. Questions totaling 10,9,9,12, and 1 were asked orally of an official from MAAIF, NARO, MAK, seed companies, and smallholder farmers, respectively (Supplementary Table S2). Questions were structured to determine roles, activities, contributions, and challenges among various participants in the tomato seed industry. Data were collected from 30 June to 11 July 2015 for smallholder farmers and between 2 August and 5 August 
2015 for MAAIF, NARO, MAK and seed company officials. Face-to-face meetings between researcher and respondents were utilized during data collection. Surveys for MAAIF, NARO, MAK, and seed company officials were completed in English, while smallholder surveys were translated into and asked in Lusoga (the native language in Kamuli District) by the first author. Research assistants who assisted with conducting farmer surveys were fluent in Lusoga and English and questions were asked in Lusoga.

\subsection{Data analysis}

Data from surveys were summarized and \% calculations obtained using Microsoft Excel ${ }^{\circledR}$ (Microsoft, Redmond, WA, USA). Both qualitative and quantitative research methods were utilized to obtain information on seed system contacts and linkages for mapping, and the seed conditioning processes used by seed companies. Data were entered into Microsoft Excel ${ }^{\circledR}$ and transferred to SPSS (release 11.0, SPSS Inc., Chicago, IL, USA) for descriptive analysis.

\subsection{Seed companies}

After conducting the tomato seed value chain analysis, we concentrated on select key participants (seed companies) to understand their activities and how these affected seed quality and distribution. Representatives from individual tomato seed companies were surveyed with an aim to establish their current tomato seed conditioning processes and procedures for ensuring production of good quality seed. Surveys with the representatives were conducted in June and July 2016. Seven companies sold tomato seed in Uganda, and six companies (three with Ugandan-parent companies, and three with Kenyan-parent companies) were involved in this study. Kenyan parent companies were included in this research because Kenya is a primary source of seed for Uganda. Kenyan seed companies have their main tomato production and conditioning locations in Kenya.

\subsection{Survey instrument for seed companies}

In addition to research approvals from Iowa State University (IRB ID:15-374) and Uganda (UNCST: A 501), approval was obtained from the National Commission for Service, Technology and Innovation (NACOSTI/P/16/96774/12104) in Kenya for surveys of the three Kenyan-parent seed companies with offices in Uganda and Kenya. Face-to-face meetings between the researcher and respondents were utilized in answering six open- and closed- ended questions during the study. Survey questions were asked about seed production and conditioning processes, quality assurance for each process, and challenges encountered during these activities. Surveys were conducted orally in English because the researcher and all respondents spoke English fluently. Observations of seed warehouses and seed conditioning equipment for three of six seed companies were conducted in Kenya (2) and Uganda (1).

\section{Results and discussion}

\subsection{Overview of Uganda's tomato seed systems}

Uganda's tomato seed industry is comprised of formal and informal seed systems. Public and private agencies in both seed systems make up the tomato seed value chain. Uganda's seed value chain involves activities from the production of genetic resources (cultivars) to the marketing or distribution of seed of a particular cultivar and quality to the end-user. In Uganda most end-users are smallholder farmers. This seed value chain analysis identified operators, service providers and their activities in the seed chain, and the enabling environment. Operators in seed value chains contributed value through cultivar development, seed production, seed multiplication, and marketing/distribution, among other activities. The value added by the operators was done through formal channels (such as commercial seed companies, NARO, or MAK) or through informal channels that included supply from other farmers or farmer-saved seed. Others that provided services within seed value chains offered rural extension (knowledge transfer) or outreach services 
about seed, cultivar testing and release, quality assurance through research, seed conditioning, packaging and storage during seed production processes, financial services and management, and promotion of marketing information. An enabling environment guides linkage among operators and between service providers and operators (Audet-Bélanger et al., 2013). Linkages indicate relationships between value chain participants and facilitating these linkages can strengthen seed systems. Linkages between value chain participants were either present (some contribution/relationship between value chain participants) or absent (no contribution/ relationship between value chain participants) or partial (not all participants noted contribution/relationship).

The role of public institutions and the private sector in the Ugandan tomato seed value chain and the challenges they faced are described below. Public institutions included MAAIF, NARO, and MAK, while the private sector was comprised of commercial seed companies, distributors, agricultural dealers (agro-dealers) and smallholder farmers (Table 1). Each of the sectors played a vital role and was involved in various activities within the tomato seed industry in Uganda. The roles of each institution and challenges faced during the implementation of activities are indicated in Table 2. Locations of seed sellers where smallholder farmers bought seed are listed in Table 3. Linkages between key participants in the tomato seed value chain, as constructed from the survey responses are provided (Supplementary Table S1).

\subsection{Public institutions}

The primary role of MAAIF is to regulate Uganda's seed industry through its department of crop inspection and certification. Policy formulation and regulation are additional roles MAAIF performed and in October 2018, MAAIF released the finalized national seed policy document (MAAIF, 2018). This document underlies policy formulation going forward. MAAIF inspects seed companies and their propagators (plant growers who produce seed) to enhance seed quality, in addition to issuing import- and export- permits. Through its national seed testing laboratory in Kawanda, MAAIF conducts seed testing and certification. A MAAIF representative stated that high volumes of informal seed (farmer-saved seed) on the market and few seed inspectors made regulation difficult (Table 2). The national seed policy (MAAIF, 2018) indicated that smallholder farmers' reliance on home-saved seed is caused by insufficient availability of affordable high-quality seed and lack of trust in the certified seed available on the market.

Table 1. Key participants involved in the tomato seed industry in Uganda and their type of institution and program specifics.

\begin{tabular}{|c|c|c|}
\hline Name of participant & $\begin{array}{l}\text { Type of } \\
\text { institution }\end{array}$ & Program specifics \\
\hline $\begin{array}{l}\text { Ministry of Agriculture, Animal } \\
\text { Industry and Fisheries }\end{array}$ & Public & $\begin{array}{l}\text { Department of crop inspection and certification; responsible for all } \\
\text { seed, including tomatoes; located in Wakiso District. }\end{array}$ \\
\hline $\begin{array}{l}\text { National Agriculture Research } \\
\text { Organization }\end{array}$ & Public & $\begin{array}{l}\text { Horticulture and oil palm program; involved in the tomato seed } \\
\text { industry through research and breeding; located in Wakiso District. }\end{array}$ \\
\hline Makerere University & Public & $\begin{array}{l}\text { Department of agriculture production in the college of agricultural } \\
\text { and environmental sciences; involved in the tomato seed industry } \\
\text { through seed research and training of university students (future } \\
\text { professionals); located in Kampala District. }\end{array}$ \\
\hline Private seed companies & Private & $\begin{array}{l}\text { Six of seven seed companies are involved in the tomato seed } \\
\text { industry; three of six companies are based in Uganda and three have } \\
\text { parent companies based in Kenya with offices and distributors in } \\
\text { Uganda. }\end{array}$ \\
\hline Distributors/agro-dealers & Private & $\begin{array}{l}\text { Enterprises involved in distribution of tomato seed; located within } \\
\text { Kampala and other districts in Uganda. }\end{array}$ \\
\hline Smallholder farmers & Private & $\begin{array}{l}\text { Users of tomato seed; located throughout rural Uganda; study } \\
\text { focused in the Kamuli District in eastern Uganda. }\end{array}$ \\
\hline
\end{tabular}


Table 2. Key participants and their roles and challenges stated in the tomato seed industry in Uganda.

\begin{tabular}{|c|c|c|}
\hline Key participant/institution & Role of institution & $\begin{array}{l}\text { Challenges stated by key participants/ } \\
\text { institutions }\end{array}$ \\
\hline $\begin{array}{l}\text { Ministry of Agriculture, } \\
\text { Animal Industry and } \\
\text { Fisheries }\end{array}$ & $\begin{array}{l}\text { Seed policy formulation } \\
\text { Seed quality assurance } \\
\text { Inspection of seed companies } \\
\text { and seed producers of these } \\
\text { companies } \\
\text { Seed testing and certification }\end{array}$ & $\begin{array}{l}\text { High volumes of informal seed (farmer-saved seed) } \\
\text { on the market } \\
\text { Limited number of seed inspectors to conduct } \\
\text { inspections }\end{array}$ \\
\hline $\begin{array}{l}\text { National Agriculture Research } \\
\text { Organization }\end{array}$ & $\begin{array}{l}\text { Seed-related research } \\
\text { Breeding of new cultivars } \\
\text { Seed multiplication }\end{array}$ & $\begin{array}{l}\text { Inadequate skilled farmers to multiply breeders' } \\
\text { foundation seed } \\
\text { Limited platforms for various tomato seed value } \\
\text { chain players to interact } \\
\text { No policy to bring all value chain players together } \\
\text { for a common goal }\end{array}$ \\
\hline Makerere University & $\begin{array}{l}\text { Education and training on } \\
\text { seed-related practices } \\
\text { Seed-related research } \\
\text { Breeding of new cultivars }\end{array}$ & $\begin{array}{l}\text { Inadequate government support for research and } \\
\text { outreach } \\
\text { High demand and limited availability/supply of } \\
\text { improved (disease resistant and high-yielding) } \\
\text { cultivars }\end{array}$ \\
\hline Private seed companies & $\begin{array}{l}\text { Seed importation } \\
\text { Seed conditioning } \\
\text { Seed quality assurance (purity } \\
\text { and germination) } \\
\text { Seed packaging } \\
\text { Seed marketing } \\
\text { Seed multiplication } \\
\text { Farm trials } \\
\text { Seed-related research }\end{array}$ & $\begin{array}{l}\text { Inaccessible roads to rural areas to enhance proper } \\
\text { seed distribution } \\
\text { Inadequate market for seeds } \\
\text { Insufficient policy enforcement of sales of seed } \\
\text { that are not the stated cultivar } \\
\text { Some distributors removing seeds from original } \\
\text { containers, reducing seed quality } \\
\text { Very few seed distributors }\end{array}$ \\
\hline Distributors/agro-dealers & Distribute, retail, and sell seed & $\begin{array}{l}\text { Low volumes of seed leading to low profit margins } \\
\text { Bulk packaging of seed with large amounts that are } \\
\text { not purchased by smallholder farmer/end users of } \\
\text { seed }\end{array}$ \\
\hline Smallholder farmers & $\begin{array}{l}\text { End users of seed } \\
\text { Participate in farm trials }\end{array}$ & $\begin{array}{l}\text { Inadequate extension assistance (knowledge } \\
\text { transfer) }\end{array}$ \\
\hline
\end{tabular}

Table 3. Locations of seed sellers where smallholder tomato farmers purchased tomato seed, Kamuli District, Uganda.

\begin{tabular}{ll}
\hline Seed source location & Tomato farmers (\%) $^{\mathbf{1}}$ \\
\hline Purchase location (one seller) & \\
$\quad$ Local rural trading center or village in Kamuli District & 23 \\
Local town in Kamuli District & 63 \\
Kampala & 1 \\
Other cities (Jinja and Kayunga) & 1 \\
Purchase location (two different sellers) & 12 \\
$\quad$ Local rural trading center or village in Kamuli District & \multicolumn{1}{|c}{ 12 } \\
\hline \% of 220 farmers who purchased and did not save tomato seed; 220 farmers of 346 survey participants.
\end{tabular}


NARO's role was identified to oversee agriculture- and seed-related research activities within Uganda. NARO's activities include tomato breeding, seed multiplication to obtain foundation seed (seed grown for genetic purity and identity), screening new tomato cultivars for yield and attributes of disease resistance, and releasing cultivars to Ugandan farmers. NARO provides agricultural outreach services to farmers involved in on-farm field trials to test new tomato cultivars. The lack of skilled farmers to conduct seed multiplication (to obtain foundation seed from breeder seed) and limited platforms and policies to unite participants of the seed value chain for a common goal have made NARO's role in these areas more difficult (Table 2). Mastenbroek and Ntare (2016) reported that NARO, as an agriculture research institution, faces the challenge of limited resources for cultivar development and promotion, maintenance, and irrigation for continuous production of breeder seed (seed controlled by the original plant breeding of NARO) to meet the increasing demand for foundation seed (i.e. seed used to increase, maintain, and distribute genetically pure seed of cultivars).

MAK's role through its department of agricultural production in the college of agricultural and environmental sciences is to conduct seed-related research and training and outreach on seed-related practices. MAK also conducts seed multiplication of improved tomato cultivars, such as its recent selection MT 56, and works to make the seeds available to smallholder growers in some regions of Uganda, either directly or indirectly through advertisements at national agricultural exhibition shows (Table 2). High demand for more improved tomato cultivars along with inadequate support for continued research and release of these improved cultivars have made implementation of MAK's seed-related research, training and outreach more difficult (Table 2).

\subsection{Private sector}

Our results indicated that commercial seed companies provide the majority of tomato seed in the Ugandan market through importation from various countries, including Kenya, Tanzania, South Africa, Denmark, the Netherlands, United Kingdom, Israel, Italy, France, United States of America, Chile, Japan, Philippines, China, and India. In most cases, breeding activities of the imported cultivars are conducted by the private or public sectors in the exporting country or elsewhere. For example, tomato cultivars Tanya and Tengeru 97 are available on the Ugandan market but were bred by the world vegetable center, whose African regional location is Arusha, Tanzania (Ojiewo et al., 2010). A previous baseline survey between 2004 and 2009 showed a total of $52,789 \mathrm{~kg}$ of tomato seeds were imported into Uganda (Ssebuliba, 2010). Seed companies indicated in survey responses that they conducted on-farm trials of breeding selections and cultivars, seed-related research, seed multiplication and conditioning, quality assurance, repackaging, storage, and distribution/ marketing. Seed companies encountered challenges of poor infrastructure (roads), which made accessibility to rural areas to conduct seed distribution difficult; inadequate markets and insufficient demand for seeds; too few and untrained seed distributors; and insufficient government inspections to reduce seeds that are not the stated cultivar on the market. Some distributors/agricultural (agro-) dealers removed seeds from original containers to smaller containers which exposed seeds to unfavorable conditions and reduced seed quality (Table 2). Mastenbroek and Ntare (2016) reported that seed companies in Uganda often face inadequate skilled labor, especially breeders, seed technologists, and horticulturists, and unenforceable contracts with various smallholder farmers who serve as propagators with scattered small pieces of land. A combination of these factors prevents seed companies from performing effectively. Ssebuliba (2010) and Uganda's national seed policy (MAAIF, 2018) also identified poor infrastructure, such as roads and limited transportation facilities, as hurdles affecting efficient seed marketing and distribution of tomato seed.

Distributors/agro-dealers are involved in retail and wholesale marketing of tomato seed. They exist as individual entities or as part of seed companies. A challenge encountered by agro-dealers was the low volume of seed traded, leading to low profit margins due to the small scale of operation (Table 2).

Smallholder farmers are the end-users (consumers) of tomato seed and also participated in conducting onfarm trials for seed companies and NARO. These farmers mentioned that one of the challenges they faced was inadequate technical assistance for cultivar evaluation (Table 2). Other farmers faced limited access to vital information and knowledge about where to access good quality seed. Uganda's recently released 
national seed policy by MAAIF (2018) concurs with our findings and also reports that weak linkages exist between research and knowledge transfer. The lack of integration between research and knowledge transfer can potentially hinder farmers from benefiting from extension assistance and high-quality seed. Smallholder farmers in the Kamuli District obtained tomato seed from various sources including purchasing from a local rural trading center or village (23.18\%), Kamuli town seed sellers (63.18\%), seed distributors in Kampala $(0.90 \%)$, other towns $(0.90 \%)$, or more than one seed source $(11.81 \%)$ (Table 3$)$.

\subsection{Seed value chain and linkages between participants}

Results from the survey of key participants indicated the various functions of the tomato seed value chain, including both formal and informal seed sectors, and are described below in the value chain (Figure 1).

\section{- Input (seed) supply}

Within the formal seed sector, tomato seed was imported by commercial seed companies from various countries all over the world (Figure 1). NARO introduced seeds into the value chain by breeding and multiplying breeder seed to obtain foundation seed. Within the informal seed sector, smallholder farmers obtained seed by saving their own seed from tomato fruits, purchasing seed from local individual farmers, or directly purchasing seed for production from seed distributors/agro-dealers or seed companies.

\section{- Seed quality regulation and certification}

MAAIF through its National Seed Certification Service regulated and certified seed quality. Seed certification was performed before and after seed importation through seed quality testing (Figure 1). Some seed companies conducted independent seed quality tests for germination. Testing added value to the seeds by improving seed quality, which could potentially result in higher prices for seeds. Although linkages such as market

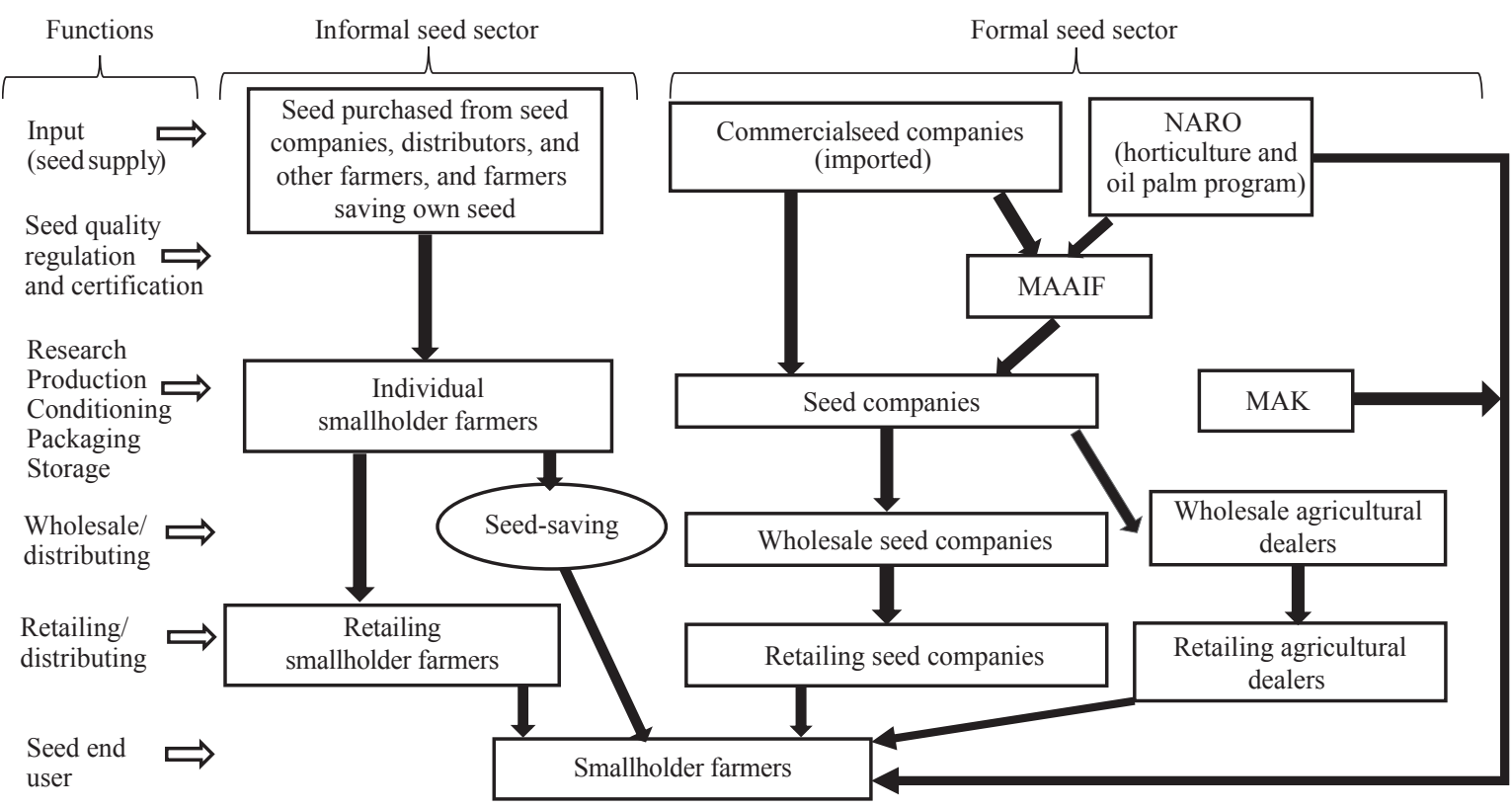

Figure 1. Seed value chain map of the tomato seed industry in Uganda, including functions and informal and formal seed sectors, based on surveys of key participants. MAAIF = Ministry of Agriculture, Animal Industry and Fisheries; NARO = National Agricultural Research Organization; MAK = Makerere University. Solid arrows indicate the flow of seed from one point to another within seed sectors. 
seed surveillance and regulation existed between seed companies and MAAIF (Supplementary Table S1), inadequate inspection and supervision of their facilities by MAAIF and difficulty in assuring seed quality in the market without inspection limited MAAIF's effectiveness in regulating and certifying seed. Additionally, MAAIF officials encountered challenges associated with having a limited number of seed inspectors in addition to limited resources to support its activities. Our findings are consistent with those identified by Daly et al. (2016). They reported that MAAIF was not able to effectively regulate seed companies and distributors, resulting in the sale of seed that was not the stated cultivar. The recently released national seed policy by MAAIF (2018) emphasized that inadequate human and financial capacities have hampered the ability of MAAIF to sufficiently monitor field seed production and conditioning for quality control, which has reduced competitiveness in local, regional, and international seed markets.

Within the informal seed sector, seed saved by smallholder farmers was highly unregulated when sold or personally used or shared. Seed typically did not have proper conditioning and storage, leading to low-quality seeds on the local market, and some seed was not the stated cultivar.

\section{- Seed production, conditioning and research}

Although seed companies with parent facilities in Kenya completed their own seed production and importation, all companies in Uganda and Kenya handled their own seed cleaning, repackaging, and storage. The processes involved in seed conditioning added value to seed by improving its quality. NARO and MAK primarily were involved in research (Figure 1), and both were involved in supplying some seed directly to farmers, including through outreach and extension. A linkage between NARO and some seed companies existed; one of six seed companies mentioned that they partner with NARO to conduct seed trials during cultivar evaluations. No linkage existed between MAK and seed companies (Supplementary Table S1). MAK is involved in seed multiplication of improved tomato cultivars and they make seed available to smallholder farmers through outreach activities. Closer linkages between MAK and seed companies would be an asset because seed companies would benefit from both from research conducted by MAK as well as MAK's training of future seed technologists.

\section{- Seed distribution (wholesale and retail)}

Tomato seeds were distributed by either departments with distribution roles within seed companies or agricultural dealers (Figure 1). A linkage existed between MAAIF and seed companies and agricultural dealers because MAAIF as a regulatory body was responsible for licensing seed distributors, enabling them to operate. No linkage existed between MAK and distributors (Supplementary Table S1), but distributors could improve their seed practices and marketing strategies with research by MAK.

\section{- Seed end user}

As end-users of seed, smallholder farmers were linked to other value chain participants and were affected by the activities of each participant (Figure 1). Although NARO, MAK and MAAIF officials mentioned that they assisted smallholder farmers with seed-related outreach services and farmers provided feedback about seed quality, Kamuli District farmers did not agree with those statements. Instead, the farmers reported that they rarely interacted with officials from NARO, MAAIF and MAK. Perhaps NARO, MAK and MAAIF's work had not involved all districts within Uganda including Kamuli. Clearly, an information gap existed between NARO, MAAIF and MAK and smallholder farmers in the Kamuli District. Lack of clear and transparent linkage may have negative implications for distributing quality seed, transferring seed-related knowledge, and input to policy makers and researchers about farmers' needs. However, smallholder farmers did purchase seeds from MAK, NARO, and seed companies, and acted as seed propagators. 


\subsection{Maintaining seed quality}

Within the seed value chain, seed companies played a vital role in seed conditioning processes because companies were the main providers of tomato seed within the formal seed sector in Uganda. All six companies were functional within Uganda; three of six had parent companies based in Kenya and exported tomato seed to Uganda. Companies' quality goals and conditioning processes of seeds and challenges encountered during seed conditioning are presented in Table 4.

\section{- Seed quality goals}

All six seed companies (100\%) considered seed germination as the primary goal for seed quality (Table 4). $83 \%$ of company respondents considered additional seed quality attributes, such as genetic identity, and freedom from noxious weed seeds, diseases, insects, soil, debris, and chaff. Four of six seed companies (66.7\%) reported that seed moisture content was an important consideration for seed quality and three of these four were based in Kenya. Only one Ugandan-based seed company considered seed moisture content as important, yet seed moisture content is one of the most significant factors negatively affecting tomato seed quality. High seed moisture content encourages fungal growth and insect activity, both of which are detrimental and can destroy the embryo of the seed and reduce germination and seedling vigor (Yanping et al., 2000). A $1 \%$ decrease in the moisture content to achieve a value between 5-14\% doubles the life of a seed (Harrington, 1960). 50\% of seed companies considered purity and freedom from mechanical damage

Table 4. Goals for seed quality, seed conditioning processes, and challenges during seed conditioning of six tomato seed companies based in Uganda and Kenya and selling seed in Uganda.

\section{$\%$ of seed companies agreeing to response}

Goals for seed quality

Germination 100

Freedom from noxious weeds

Freedom from disease

Freedom from insect parts

Freedom from soil, other debris and chaff $\quad 83.3$

$\begin{array}{ll}\text { Seed moisture content } & 66.7\end{array}$

Purity $\quad 50$

Freedom from mechanical damage $\quad 50$

Embryo condition $\quad 16.7$

$\begin{array}{ll}\text { Seed color } & 16.7\end{array}$

Seed conditioning processes

Importation/received 100

Bulk storage $\quad 100$

$\begin{array}{lr}\text { Drying } & 16.7\end{array}$

Cleaning $\quad 16.7$

Separating and upgrading $\quad 16.7$

$\begin{array}{lr}\text { Seed treatment } & 16.7\end{array}$

Repackaging $\quad 100$

Storage 100

Challenges during seed conditioning

Inadequate supervision from the ministry of agriculture $\quad 50$

Technology is not up to date $\quad 50$

Inadequate processing equipment 33.3

Inadequate skilled personnel $\quad 33.3$

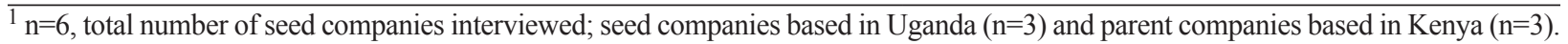


as important. One company (16.7\%) based in Kenya reported embryo condition and seed color as qualities they consider important while conducting seed conditioning (Table 4). Generally, seed companies based in Kenya considered more seed quality attributes as goals while conducting seed conditioning compared to Ugandan seed companies.

\section{- Seed production and conditioning processes}

Seed conditioning included all the practices of processing seeds. All companies (100\%) imported tomato seed and one company based in Kenya imported and produced its own seed. Seed was bulk-stored after companies received it. During bulk storage, three of six companies $(50 \%)$ controlled temperature at $20-40{ }^{\circ} \mathrm{C}$, $18^{\circ} \mathrm{C}$, or $25-30{ }^{\circ} \mathrm{C}$, and only one of these three companies controlled relative humidity, at $74 \%$. These seed storage temperatures and relative humidity used by two Ugandan seed companies and one Kenyan company were higher than the recommended values for storage temperatures $\left(8-15^{\circ} \mathrm{C}\right)$ and relative humidity $(30$ $50 \%$ ), and compromised seed quality (Harrington, 1960). High temperature during seed storage reduces seed longevity because it increases the seed respiration rate and metabolic, biochemical, and physiological processes, which lead to seed deterioration. Deteriorated seeds produce weak seedlings during germination (Elias and Copeland, 1994; Kapoor et al., 2010). An increase of $5{ }^{\circ} \mathrm{C}$ in temperature reduces the life of a seed by 50\% (Miller and Lawrence, 1998). Three of six seed companies lacked cold rooms and storage equipment, which can be detrimental to seed quality, especially if seed is stored for a long period of time. Cold rooms facilitate lower seed storage temperatures $\left(<5^{\circ} \mathrm{C}\right)$, slow down metabolic processes, and reduce seed deterioration, thereby increasing seed longevity (Elias and Copeland, 1994; Nassari et al., 2014).

Seed sampling and germination tests were conducted by individual seed companies and the MAAIF national seed testing laboratory for companies based in Uganda, and the Kenya Plant Health Inspectorate Services (KEPHIS) for companies based in Kenya. Ugandan-based companies tested only for germination while Kenyan-based companies conducted more tests including physical and genetic purity and seed moisture content and vigor. Within Kenya, test results by individual seed companies and KEPHIS were compared and if no discrepancies occurred, seed was packaged for sale. Some seed company officials in Uganda mentioned that they depended on the seed-exporting countries to conduct additional screening and tests of seeds' physical state, genetic purity, and moisture content, before any seed was exported to Uganda. This implied that Ugandan seed companies were not completely certain of the quality of seed imported into Uganda and depended on the country of origin. Ugandan-based companies (33\%) lacked adequate seed conditioning equipment (Table 4) and were not able to conduct independent seed quality tests. The Kenyan-parent company that produced its own seed also conditioned the seed by drying, cleaning, separating, upgrading by adding any seed treatments, packaging, and storage. Seed quality during these processes was ensured by adhering to quality standards enforced by the company's seed quality laboratory as well as KEPHIS.

\subsection{Challenges faced by seed companies during seed conditioning}

The most common challenges faced by $50 \%$ of seed companies during seed conditioning were inadequate supervision and inspection of facilities by MAAIF's Department of Crop Inspection and Certification and limited access to the latest seed conditioning and quality testing technology. A MAAIF representative stated a lack of financial assistance and few skilled personnel to conduct inspections and supervise seed companies. Additional challenges mentioned by two of six seed companies were inadequate seed conditioning equipment and inadequate skilled personnel to conduct seed conditioning processes (Table 4). The above challenges led to difficulties in regulating and staffing seed companies and compromised tomato seed quality.

\section{Conclusions}

Survey responses of key participants identified their major roles in the tomato seed value chain in Uganda, which included MAAIF for regulation and certification; NARO for breeding and multiplication; MAK for seed-related research; commercial seed companies for importation and conditioning; seed distributors for 
seed sales (wholesale and retail); and smallholder farmers as seed savers and end-users of seed. Linkages existed between NARO and MAAIF and seed companies and between MAAIF and seed companies and their wholesale and retailing seed companies (distributors). Partial linkages were found between retailing seed companies (distributors) and smallholder farmers, and no linkages existed between MAK and seed companies and between NARO, MAK, MAAIF and smallholder farmers in Kamuli. Although NARO and MAK developed cultivars for farmers, Kamuli farmers did not state the linkage. This study is the first to identify and report key information on Uganda's tomato seed value chain. Results could be refined as a model for additional vegetable species and also used to inform Uganda's current national seed policy.

Commercial seed companies imported all tomato seeds sold through the formal sector in Uganda, a result that indicates little or no commercial domestic seed production. All six companies surveyed stated germination was the primary goal for quality and seeds were conditioned for germination. Other seed quality attributes were not considered as goals for conditioning by all companies, although three of six companies monitored temperature and one of these monitored relative humidity during bulk storage, but optimal environmental conditions were not achieved. Ugandan-parent companies tested only for germination and depended on exporting companies or countries to conduct any additional seed quality tests. Kenyan-parent companies completed additional seed quality tests, including physical and genetic purity, moisture content, and seedling vigor. Seed companies faced several major challenges including inadequate supervision and regulation from MAAIF and limited access to the latest seed conditioning and quality testing technology for Ugandan-parent companies. High quality seed from commercial Ugandan-parent companies can be achieved only through further investment in seed conditioning equipment and seed management, as done by Kenyan-parent companies. Additional investments will allow Ugandan companies to monitor and achieve appropriate temperature and relative humidity conditions during bulk storage in order to maintain quality. Improved seed management practices and training seed technologists for testing after importation into Uganda would provide the ability to confirm quality and reject any poor-quality imported or improperly stored seed, before its sale.

The evidence collected in our surveys indicates that MAAIF could play an important role in improving the seed system by focusing on implementation of seed policy and regulation of seed companies and distributors. As federal agriculture agencies, MAAIF and NARO are well positioned to oversee training of smallholder farmers to consider advantages of using professionally produced seed, and, if farmer income is limited, transfer knowledge about how to use seed conditioning and proper seed-saving techniques. NARO can play an important role by facilitating training of more farmers on seed multiplication so as to increase quantities of foundation seed. MAK strengthens linkages between the formal sector participants and the smallholder farmers through strengthening the training and education of seed science professionals, and in seeking financial support for additional research and outreach programs associated with seeds and tomato production. The results also suggest potential opportunities for Ugandan-parent seed companies to explore whether any competitive advantages exist were they to grow and produce seed in Uganda instead of relying on seed produced in Kenya and other countries and world regions.

Future research could focus on how to address barriers that exist among participants of the tomato seed value chain, so that they may work together to ensure proper and efficient distribution of seed. An emphasis could be to develop and support an umbrella organization to bring all the value chain participants for vegetable seeds together to achieve a common goal of improved seed quality throughout the seed system. Detailed responses of surveys of the seed system indicate the potential for Ugandan vegetable seed companies to add value to the seed through additional seed conditioning processes. Future investigation may more clearly identify which roles MAAIF could play in supporting the enhancement of successes for seed companies. 


\section{Supplementary material}

Supplementary material can be found online at https://doi.org/10.22434/IFAMR2019.0199

Figure S1. Map of Uganda indicating location of the study area.

Table S1. Survey questions asked of key participants to determine linkages for the tomato seed value chain in Uganda.

Table S2. Interview questions asked in surveys of six seed companies, two federal agencies, one national university, and 346 smallholder farmers in Uganda in 2015.

Sample size and techniques

\section{References}

Audet-Bélanger, G., M.H. Thijssen, P. Gildemacher, A. Subedi, W.S. De Boef and W. Heemskerk. 2013. Seed value chain analysis. ISSD technical notes no 2. Wageningen Centre for Development Innovation, Wageningen UR, Wageningen, the Netherlands, 10 pp.

Center for Environmental and Agricultural Policy Research, Extension, and Development (CEAPRED). 2014. Internal assessment for vegetable seed project (VSP) III. CEAPRED, Kathmandu, Nepal, pp. 17.

Daly, J., H. Danny, G. Gereffi and A. Guinn. 2016. Maize value chains in East Africa. F-38202-RWA-1. Center on Globalization, Governance, and Competitiveness, Duke University, Durham, NC, USA.

Elias, S.G. and L.O. Copeland. 1994. The effect of storage conditions on canola Brassica napus L. seed quality. Journal of Seed Technology 18(1): 21-29.

Fisher A., J. Laing and J. Stoekel. 1983. Sampling and sample size determination. In: Handbook for family planning operations research design. Population Council, New York, NY, USA, pp. 42-46.

Gauchan D., D.B. Thapa Magar, S. Gautam, S. Singh and U.S. Singh. 2014. Strengthening seed system for rice seed production and supply in Nepal. Socioeconomics and Agricultural Research Policy Division, Nepal Agricultural Research Council, Government of Nepal, Khumaltar, Nepal, 40 pp.

Harrington, J.F. 1960. Drying, storing and packaging seed to maintain germination and vigor. Seedsmen's Digest 11(1): 16.

Hellin, J. and M. Meijer. 2006. Guidelines for value chain analysis. Food and Agriculture Organization of the United Nations, Rome, Italy, $24 \mathrm{pp}$.

Kansiime, M.K. and A. Mastenbroek. 2016. Enhancing resilience of farmer seed system to climate-induced stresses: insights from a case study in West Nile region, Uganda. Journal of Rural Studies 47: 22-230.

Kapoor, R., A. Arya, M.A. Siddiqui, A. Amir and H. Kumar. 2010. Seed deterioration in chickpea (Cicer arietinum L.) under accelerated ageing. Asian Journal of Plant Sciences 9(3): 158-162.

Larson, D.W. and S. Mbowa. 2004. Strategic marketing problems in the Uganda maize seed industry. International Food and Agribusiness Management Review 7(4): 86-93.

Lwakuba, A. 2012. The seed sector of Uganda: is the future of the small-scale farmer bleak or bright. A review of the seed sector in Uganda. Pelum Association, Misereor, Kampala, Uganda, 29 pp.

Mastenbroek, A. and B. Ntare. 2016. Uganda early generation seed study: unlocking pathways for sustainable provision of EGS for food crops in Uganda. Centre for Development Innovation, Report CDI-16-030, Wageningen UR, Wageningen, the Netherlands.

Miller, B.M. and C. Lawrence. 1998. Seed production principles and practices. CBS Publishers and distributors, New Delhi, India, pp. 132-133.

Ministry of Agriculture, Animal Industry and Fisheries (MAAIF). 2018. National seed policy. MAAIF, Entebbe, Uganda, 22 pp.

Mugenda, O.N and A.G. Mugenda. 1999. Research methods: a quantitative and qualitative approach. African Center for Technology Studies Press, Nairobi, Kenya.

Nassari. P.J., K. Keshavulu, R. Manohar, K.S.R. Chandra and A. Raheem. 2014. Post-harvest drying of tomato (Lycopersicon esculentum Mill.) seeds to ultra-low moisture safe for storage using desiccant (zeolite) beads and their effects on seed quality. American Journal of Research Communication 2(4): 74-83. 
Ojiewo, C., A. Tenkouano, M. Oluoch and R. Yang. 2010. The role of AVRDC - the world vegetable centre in vegetable value chains. African Journal for Horticultural Science 3: 1-23.

Sperling, L. and H.D. Cooper. 2003. Understanding seed systems and seed security. In: Improving the effectiveness and sustainability of seed relief. Proceedings of a stakeholders' workshop, Food and Agriculture Organization, Rome, Italy.

Ssebuliba, N.R. 2010. Base line survey of the seed sector in Uganda, in relation to regional harmonization of seed legislation. A report by the Uganda Seed Trade Association, Kampala, Uganda, 56 pp.

Ssejjemba, K.F. 2008. Value chain analysis of fresh tomatoes in Uganda and Kenya. Maastricht School of Management, Maastricht, the Netherlands, $17 \mathrm{pp}$.

Yanping, Y., G. Ronggi, S. Qingguan and L. Shengfu. 2000. Vigour of Welsh onion seeds in relation to storage temperature and seed moisture content. Seed Science and Technology 28(3): 817-823. 